\title{
1-O-Acetylgeopyxin A, a derivative of a fungal metabolite, blocks tetrodotoxin- sensitive voltage-gated sodium, calcium channels and neuronal excitability which correlates with inhibition of neuropathic pain
}

Yuan Zhou ${ }^{1,2}$, Song Cai ${ }^{2}$, Kimberly Gomez ${ }^{2}$, E. M. Kithsiri Wijeratne ${ }^{3}$, Yingshi $\mathrm{Ji}^{2}$, Shreya S. Bellampalli², Shizhen Luo ${ }^{2}$, Aubin Moutal ${ }^{2}$, A. A. Leslie Gunatilaka ${ }^{3}$ and Rajesh Khanna ${ }^{2,4,5^{*}}$ (D)

\begin{abstract}
Chronic pain can be the result of an underlying disease or condition, medical treatment, inflammation, or injury. The number of persons experiencing this type of pain is substantial, affecting upwards of 50 million adults in the United States. Pharmacotherapy of most of the severe chronic pain patients includes drugs such as gabapentinoids, re-uptake blockers and opioids. Unfortunately, gabapentinoids are not effective in up to two-thirds of this population and although opioids can be initially effective, their long-term use is associated with multiple side effects. Therefore, there is a great need to develop novel non-opioid alternative therapies to relieve chronic pain. For this purpose, we screened a small library of natural products and their derivatives in the search for pharmacological inhibitors of voltage-gated calcium and sodium channels, which are outstanding molecular targets due to their important roles in nociceptive pathways. We discovered that the acetylated derivative of the entkaurane diterpenoid, geopyxin A, 1-O-acetylgeopyxin A, blocks voltage-gated calcium and tetrodotoxin-sensitive voltage-gated sodium channels but not tetrodotoxin-resistant sodium channels in dorsal root ganglion (DRG) neurons. Consistent with inhibition of voltage-gated sodium and calcium channels, 1-O-acetylgeopyxin A reduced reduce action potential firing frequency and increased firing threshold (rheobase) in DRG neurons. Finally, we identified the potential of 1-O-acetylgeopyxin A to reverse mechanical allodynia in a preclinical rat model of HIVinduced sensory neuropathy. Dual targeting of both sodium and calcium channels may permit block of nociceptor excitability and of release of pro-nociceptive transmitters. Future studies will harness the core structure of geopyxins (Continued on next page)
\end{abstract}

\footnotetext{
* Correspondence: rkhanna@email.arizona.edu

2Department of Pharmacology, College of Medicine, University of Arizona,

1501 North Campbell Drive, P.O. Box 245050, Tucson, AZ 85724, USA

${ }^{4}$ Neuroscience Graduate Interdisciplinary Program, College of Medicine,

Tucson, AZ 85724, USA

Full list of author information is available at the end of the article
}

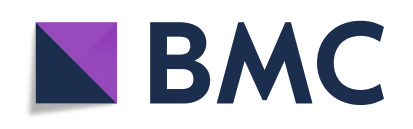

(- The Author(s). 2020 Open Access This article is licensed under a Creative Commons Attribution 4.0 International License, which permits use, sharing, adaptation, distribution and reproduction in any medium or format, as long as you give appropriate credit to the original author(s) and the source, provide a link to the Creative Commons licence, and indicate if changes were made. The images or other third party material in this article are included in the article's Creative Commons licence, unless indicated otherwise in a credit line to the material. If material is not included in the article's Creative Commons licence and your intended use is not permitted by statutory regulation or exceeds the permitted use, you will need to obtain permission directly from the copyright holder. To view a copy of this licence, visit http://creativecommons.org/licenses/by/4.0/. The Creative Commons Public Domain Dedication waiver (http://creativecommons.org/publicdomain/zero/1.0/) applies to the data made available in this article, unless otherwise stated in a credit line to the data. 
(Continued from previous page)

for the generation of antinociceptive drugs.

Keywords: 1-O-acetylgeopyxin a, Voltage-gated calcium channels, Voltage-gated sodium channels, Tetrodotoxinsensitive voltage-gated sodium channels, Excitability, Non-opioid pain-relieving therapeutics, HIV-induced sensory neuropathy

\section{Introduction}

According to the International Association for the Study of Pain, pain is an unpleasant sensory and emotional experience associated with real or potential tissue damage, which helps the body to be aware of harmful stimuli. Pain can be classified as acute and chronic. Acute pain plays a protective role. This type of pain is short in duration and disappears with the resolution of the pathological process [1]. However, it can transition into chronic pain. Chronic pain persists for a prolonged period of time and it has been estimated to affect one fifth of the world's population [2]. Chronic pain is pathological, since it is not a symptom of some disorder, but rather, originates from some disease or from a nervous system injury [3]. Although there are many treatment options available, none are universally endorsed, and many come with counterproductive side effects. An estimated $20 \%$ of patients with pain-related diagnoses (including acute and chronic pain) receive an opioid prescription. Opioids are associated with multiple side effects including respiratory depression, tolerance, dependence, hyperalgesia, constipation, and mental fog among others [4]. Due to their inefficiency and side effects they affect the quality of life of patients, thus a reduction in the prescription of opioids to treat pain, has been recommended [4]. Thus, there is a tremendous need to develop novel non-opioid pain-relieving therapeutics to provide alternative treatments to manage neuropathic pain.

In this context, in the search for bioactive and/or novel metabolites of plant- and lichen-associated fungi, we have evaluated a library of $\sim 90$ natural products isolated from Sonoran Desert plants, and some derivatives of these natural molecules. Of these, geopyxins A-F (1 through 5), a group of ent-kaurane diterpenoids encountered in endolichenic fungal strains, Geopyxis aff. Majalis and Geopyxis sp. AZ0066, and their analogs, were found to be active in cancer cell proliferation/survival and heat-shock induction assays [5]. Ent-kauranes are known to exhibit a wide range of bioactivities, with cytotoxic [6-9], anti-inflammatory [9-11], antiangiogenic [12], anti-HIV [13], antioxidant [14, 15], anticholinesterase [14], antityrosinase [15], among other properties reported. However, it has not yet been investigated whether these molecules have a therapeutic potential for pain relief.
We recently reported that betulinic acid, a bioactive fraction of the desert plant Hyptis emoryi, is antinociceptive in preclinical models of neuropathic pain via targeting of N-type and T-type voltage-gated calcium $\left(\mathrm{Ca}^{2+}\right)$ channels [16]. Likewise, we identified two plant natural products: hardwickiic acid, isolated from Salvia wagneriana, and hautriwaic acid, isolated from Eremocarpus, both of which reversed pain behaviors in experimental models of HIV-induced and chemotherapy-induced neuropathies by inhibition of voltage-gated sodium $\left(\mathrm{Na}^{+}\right)$ channels [17]. In another study, we demonstrated that physalin F, a steroidal derivative isolated from Physalis acutifolia reversed tactile hypersensitivity in models of paclitaxel-induced peripheral neuropathy and spinal nerve ligation (SNL) via blockade of R-type and N-type voltage-gated $\mathrm{Ca}^{2+}$ channels [18].

Here, our initial screening of the natural products, geopyxin $\mathrm{A}$ and geopyxin $\mathrm{C}$, and geopyxin $\mathrm{A}$ derivatives, 1-O-acetylmethylgeopyxin A, methylgeopyxin $\mathrm{A}$, and 1$O$-acetylgeopyxin A revealed that 1-O-acetylgeopyxin A inhibits voltage-gated $\mathrm{Ca}^{2+}$ channels. Total $\mathrm{Na}^{+}$currents in isolated DRG sensory neurons were also reduced by 1-O-acetylgeopyxin A, which preferentially inhibited tetrodotoxin (TTX)-sensitive $\mathrm{Na}^{+}$currents. Sensory neuron excitability was also blunted by $1-O$-acetylgeopyxin A. Finally, we identified the potential of 1 -O-acetylgeopyxin A to reverse chronic pain behavior in a preclinical rat model of HIV-Induced sensory neuropathy.

The results presented in this study illustrate the therapeutic potential for 1-O-acetylgeopyxin A management of preclinical HIV-induced neuropathy. Likewise, we identified that both voltage-gated $\mathrm{Ca}^{2+}$ and $\mathrm{Na}^{+}$channels are the pharmacological targets of 1-O-acetylgeopyxin $\mathrm{A}$. Whilst the exact subtype(s) of $\mathrm{Ca}^{2+}$ channel remains to be determined, the study illustrates the utility of targeting both sodium and calcium channels in an effort to develop blockers that simultaneously curb excitability and transmitter release.

\section{Results}

1-O-acetylgeopyxin A preferentially inhibits voltage-gated $\mathrm{Ca}^{2+}$ channels

To discover new molecules with therapeutic potential for pain relief, we screened a library of natural products for small molecules capable of targeting voltage gated 
$\mathrm{Ca}^{2+}$ channels. This was achieved using Fura2acetoxymethyl ester (Fura-AM), a ratiometric highaffinity intracellular $\mathrm{Ca}^{2+}$ indicator, in rodent sensory dorsal root ganglia (DRG) neurons. First, the neurons were challenged with $40 \mathrm{mM} \mathrm{KCl}$ (which changes the membrane voltage to $-32.2 \mathrm{mV}$ - using the Nernst equation) to trigger low voltage-activated (LVA) $\mathrm{Ca}^{2+}$ channels, i.e., Cav3.x channels) or $90 \mathrm{mM} \mathrm{KCl}$ (which changes the membrane voltage to $-11.4 \mathrm{mV}$ - based on the Nernst equation, to open high-voltage activated (HVA) $\mathrm{Ca}^{2+}$ channels, i.e., Cav1.x and Cav2.x) [19]
(Fig. 1a). Then, neurons were treated overnight with $20 \mu \mathrm{M}$ of geopyxin A, 1-O-acetylmethylgeopyxin A, methylgeopyxin A, 1-O-acetylgeopyxin $\mathrm{A}$ and geopyxin $\mathrm{C}$ (Fig. 1b). When DRG neurons were treated with 1-Oacetylgeopyxin A (Fig. 1c), we noted a significant block of $\mathrm{KCl}$-triggered calcium channel activity when neurons were challenged with 40 and $90 \mathrm{mM}$ of $\mathrm{KCl}$ ( 93 and $56 \%$, respectively, " $p<0.05$, one-way ANOVA with Dunnett's post hoc test) compared to the control $(0.1 \%$ DMSO). In contrast to the modest degree of inhibition of $\mathrm{KCl}$-triggered calcium influx with geopyxin $\mathrm{C}$ when

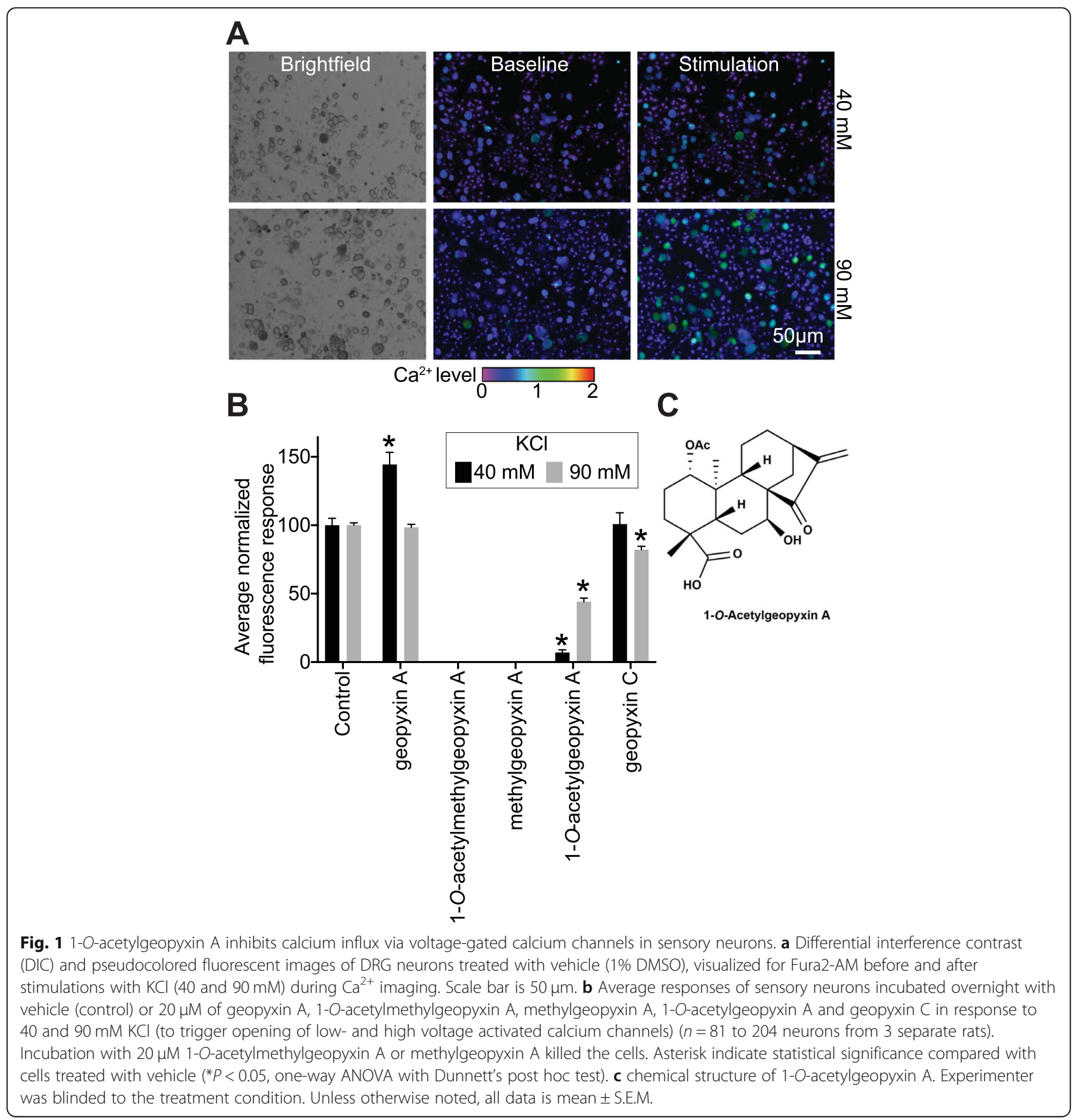


neurons were challenged with $90 \mathrm{mM}$ of $\mathrm{KCl}(\sim 15 \%$, " $\mathrm{p}<0.05$, one-way ANOVA with Dunnett's post hoc test), $\mathrm{KCl}$-triggered calcium influx was not affected by geopyxin A compared to DMSO. However, its derivatives, 1-O-acetylmethylgeopyxin $\mathrm{A}$ and methylgeopyxin A, were highly toxic to DRG neurons (Fig. 1b). These data imply that only 1-O-acetylgeopyxin A affects voltage-gated $\mathrm{Ca}^{2+}$ channels in sensory neurons.

\section{1-O-acetylgeopyxin $\mathrm{A}$ reduces total calcium currents in DRG sensory neurons}

The most potent compound from the primary calcium imaging screening was 1-O-acetylgeopyxin A (Fig. 1b), which showed nearly $\sim 93$ and $56 \%$ inhibition of $\mathrm{Ca}^{2+}$ channel influx at $20 \mu \mathrm{M}$ when sensory neurons were depolarized with 40 and $90 \mathrm{mM} \mathrm{KCl}$, respectively. Therefore, we next sought to determine how voltage-gated $\mathrm{Ca}^{2+}$ channels were affected by 1-O-acetylgeopyxin A using whole-cell patch clamp electrophysiological recordings.

Total high voltage-activated (HVA) and low-voltageactivated (LVA)) $\mathrm{Ca}^{2+}$ currents were measured from small to medium diameter rat DRG neurons. In order to do so, from a holding potential of $-60 \mathrm{mV}$, depolarization steps (200 ms step) from $-70 \mathrm{mV}$ to $+60 \mathrm{mV}$ in $10 \mathrm{mV}$ increments were applied (Fig. 2a). Typical traces in Fig. 2a show a family of $\mathrm{Ca}^{2+}$ currents recorded from DRG neurons treated overnight with control $(0.1 \%$ DMSO) $(n=21)$ or $20 \mu \mathrm{M}$ of $1-O$-acetylgeopyxin A $(\mathrm{n}=21)$. When compared to the control, 1-O-acetylgeopyxin A inhibited total $\mathrm{Ca}^{2+}$ current density with a $\sim 31 \%$ decrease in peak current density (Fig. 2b, c). The data was normalized according to capacitance of the cell in order to account for the heterogeneity of DRG neuronal populations.

Since this current decrement could be a result of changes in channel gating, we determined the effect of 1$O$-acetylgeopyxin A on activation and inactivation kinetics of DRG $\mathrm{Ca}^{2+}$ currents as described in Methods. After converting the current values to conductance $(G)$, the conductance-voltage relationship was fitted with a Boltzmann equation, and the $G$ value for each neuron was normalized to the maximal value (Gmax) derived from the fit. The G/Gmax-voltage relationship presented in Fig. $2 \mathrm{~d}$ demonstrates that there was a hyperpolarizing shift of $\sim 2 \mathrm{mV}$ in the half-maximal activation $\left(\mathrm{V}_{1 / 2}\right)$ of steadystate. While, a depolarizing shift of $\sim 3 \mathrm{mV}$ in the $\mathrm{V}_{1 / 2}$ of steady-state inactivation (protocol shown in Fig. 2d inset) in the presence of 1-O-acetylgeopyxin $\mathrm{A}$, was observed (Table 1). Thus, these results suggest that 1-O-acetylgeopyxin $\mathrm{A}$ affects total $\mathrm{Ca}^{2+}$ currents.

\section{1-O-acetylgeopyxin A reduces sodium currents in DRG sensory neurons}

Since sodium ion is a critical component in the generation of action potentials, modulating neuronal excitability and propagating nociceptive signaling, we assessed the possible action of 1-O-acetylgeopyxin A on $\mathrm{Na}^{+}$currents by whole cell voltage-clamp electrophysiology (protocols illustrated in Fig. 3a). Typical families of sodium currents from DRG neurons treated with DMSO $(n=16)$ or $1-O$-acetylgeopyxin A $(n=19)$ are shown in Fig. 3b. Overnight treatment with 1-O-acetylgeopyxin $\mathrm{A}(20 \mu \mathrm{M})$ inhibited total $\mathrm{Na}^{+}$current density with $\sim 47 \%$ decrease in peak current density (Fig. 3c, d); data displayed is normalized by cell capacitance. We next investigated the effect of 1-O-acetylgeopyxin A on the biophysical properties of voltage-dependence activation and inactivation of DRG $\mathrm{Na}^{+}$currents. Steady-state activation (Fig. 3e) and inactivation properties (Fig. 3f) of sodium currents were affected. There was a depolarizing shift of $\sim 5 \mathrm{mV}$ in the $\mathrm{V}_{1 / 2}$ with 1-O-acetylgeopyxin A (Table 1). Likewise, a depolarizing shift of $\sim 7 \mathrm{mV}$ in the $\mathrm{V}_{1 / 2}$ of steady-state inactivation (Table 1), was reported; these data shows the inhibitory function of 1-O-acetylgeopyxin $\mathrm{A}$ on $\mathrm{Na}^{+}$channels.

\section{TTX-sensitive sodium currents in DRG sensory neurons are reduced by 1-O-acetylgeopyxin $\mathrm{A}$}

$\mathrm{Na}^{+}$channels can be classified according to their sensitivity (NaV1.7) or resistance (NaV1.8 and NaV1.9) to tetrodotoxin (TTX) in DRG sensory neurons [20]. TTXsensitive (TTX-S) currents activate at low thresholds, are fast-inactivating, shape the action potential and are required for initial depolarization [20]. As distinctive inactivation kinetics distinguish TTX-resistant (TTX-R) from TTX-S $\mathrm{Na}^{+}$channels, a fast-inactivation protocol (see Methods) was used to electrically isolate TTX-R (current available following a $-40 \mathrm{mV}$ prepulse) from total current (current left after a $-120 \mathrm{mV}$ prepulse), as previously described [21]. DRG neurons were treated overnight with $20 \mu \mathrm{M}$ of 1 -O-acetylgeopyxin $\mathrm{A}$ or control (0.1\% DMSO) as indicated, subsequently TTX-R and TTX-S $\mathrm{Na}^{+}$currents were recorded and isolated. When compared to control, 1-O-acetylgeopyxin A significantly inhibits TTX-S $\mathrm{Na}^{+}$currents ( 31\%) (Fig. 4a, b). Based on different properties of the DRG TTX-S and TTX- $\mathrm{R} \mathrm{Na}^{+}$currents, TTX-R currents were estimated by a $200 \mathrm{~ms}$ test pulse to $10 \mathrm{mV}$ following $1000 \mathrm{~ms}$ prepulse at $-40 \mathrm{mV}$ to inactivate the TTX-S component. 1-Oacetylgeoyxin A did not significantly inhibit TTX-R currents (Fig. 4c, d). Thereby, we conclude that 1-O-acetylgeopyxin A effects TTX-S $\mathrm{Na}^{+}$currents in DRG neurons.

\section{1-O-acetylgeopyxin a inhibits sensory neuron excitability}

With effects on both voltage-gated sodium and calcium channels - gating of which is inextricably linked to neuronal excitability, we next assessed potential effects of expect 1-O-acetylgeopyxin A excitability properties of 

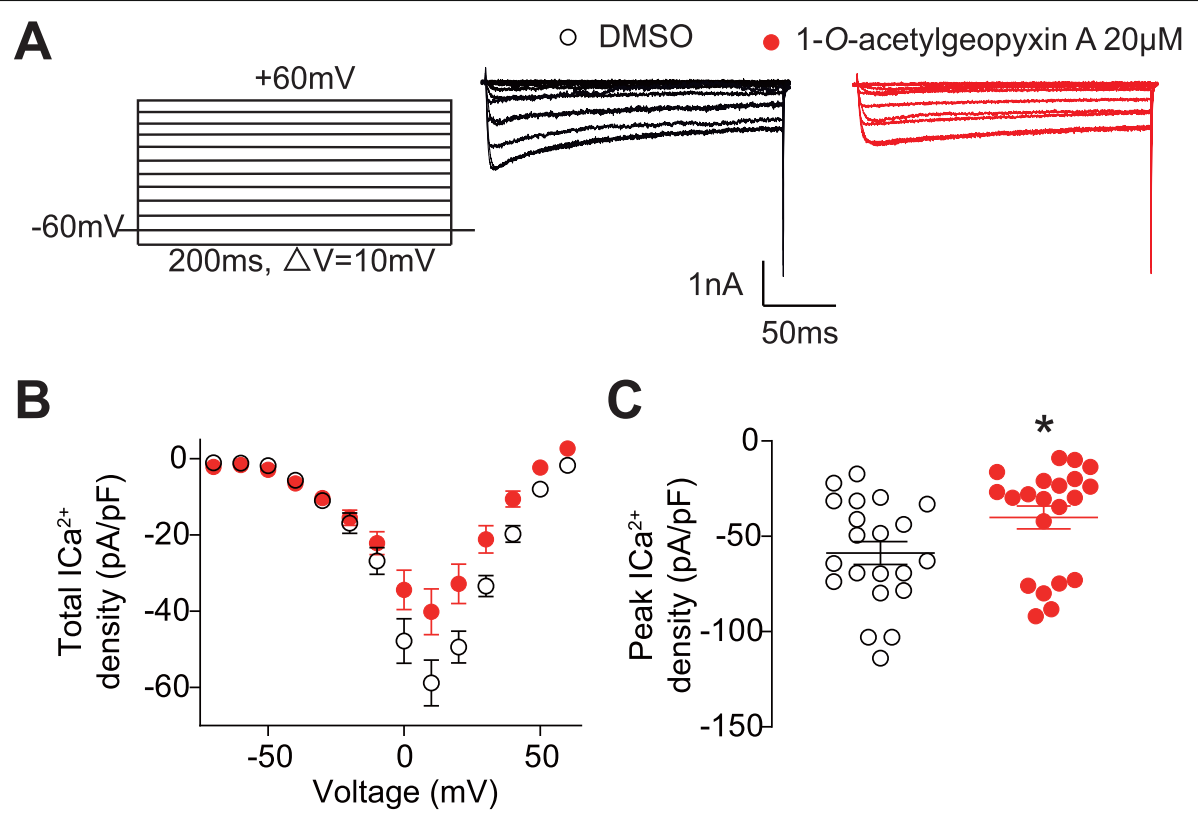

C
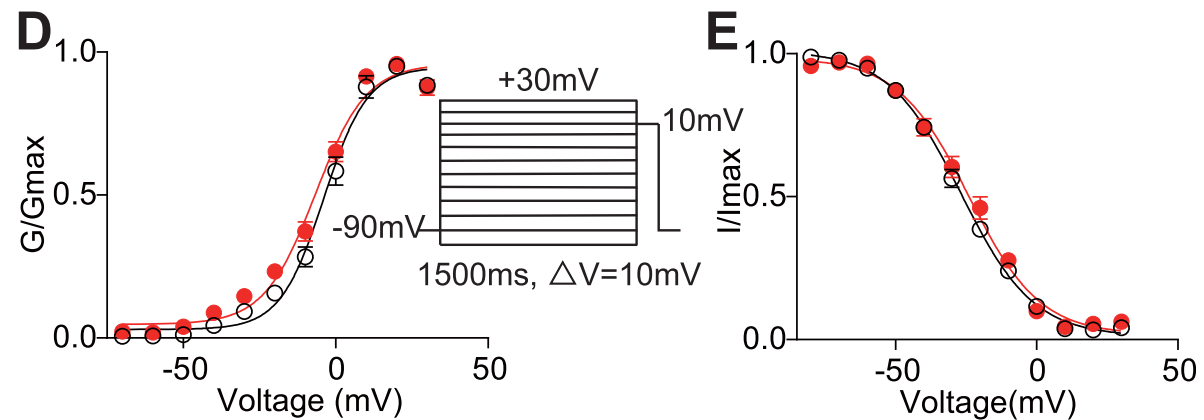

Fig. 2 1-O-acetylgeopyxin A inhibits total $\mathrm{Ca}^{2+}$ currents in dorsal root ganglion (DRG) sensory neurons. a Representative traces of total $\mathrm{Ca}^{2+}$ currents from DRG sensory neurons treated with 0.1\% DMSO (control) or $20 \mu \mathrm{M}$ 1-O-acetylgeopyxin A. Currents were evoked by $200 \mathrm{~ms}$ pulse between -70 and $+60 \mathrm{mV}$. b, c Summary of the normalized (pA/pF) total $\mathrm{Ca}^{2+}$ current density versus voltage relationship (b) and peak total $\mathrm{Ca}^{2+}$ current density at $+10 \mathrm{mV}$ (mean \pm SEM) (c) from DRG sensory neurons treated as indicated. (d, e) Boltzmann fits for normalized conductance, G/ Gmax, voltage relations for voltage dependent activation (d) and inactivation (e) of sensory neurons treated as indicated. $V_{1 / 2}$ values for activation and inactivation are presented in Table 1. Asterisks indicate statistical significance compared with cells treated with $0.1 \%$ DMSO $\left({ }^{*} P<0.05\right.$, unpaired two-tailed Student's t test, $n=21$ per condition)

sensory neurons. Consistent with the decrease in total and TTX-S $\mathrm{Na}^{+}$currents noted above, 1-O-acetylgeopyxin A application in sensory neurons resulted in decreased action potential (AP) frequency $[12.2 \pm 3.0$ for DMSO control $(n=5)$ vs. $2.8 \pm 1.4$ for 1 - $O$-acetylgeopyxin A $(n=4)$ ] (Fig. 5a, b); increased rheobase $[91.7 \pm 13.5$ for DMSO control $(n=12)$ vs. $156.3 \pm$ 17.5 for $1-O$-acetylgeopyxin $\mathrm{A}(n=8)]$, the current required to initiate an action potential (Fig. $5 \mathrm{c}, \mathrm{d}$ ); but no change in AP spike height [85.8 \pm 5.6 for DMSO control $(\mathrm{n}=12)$ vs. $81.8 \pm 5.9$ for $1-O$-acetylgeopyxin A $(n=8)$ ] (Fig. 5e). Spontaneous activity was not observed in any of the 1-O-acetylgeopyxinAtreated DRGs $(n=13$; data not shown). Together, these observations demonstrate that 1-O-acetylgeopyxin A inhibits sensory neuron excitability.
HIV-induced sensory neuropathy is alleviated by treatment with 1-O-acetylgeopyxin a

Since voltage-gated $\mathrm{Ca}^{2+}$ and $\mathrm{Na}^{+}$channels have been shown to play an important role in neuropathic pain [22-26], we then explored the potential of 1-O-acetylgeopyxin $\mathrm{A}$ in alleviating neuropathic pain in an experimental model. We selected the HIV-induced sensory neuropathy model as both calcium and voltage-gated channels have been linked to pain in this model. To test this, rats were administered with three intrathecal (i.th.) injections of the HIV-1 envelope glycoprotein (gp120) which resulted in the development of mechanical allodynia (Fig. 6a), consistent with previous reports [27, 28]. I.th injection of 1 - $O$-acetylgeopyxin A $(2 \mu \mathrm{g} / 5 \mu \mathrm{L})$ reversed mechanical allodynia $1-2 \mathrm{~h}$ post-injection and lasted for an 2 additional hours (Fig. 5a). This reversal is 
Table 1 Effects of 1-O-acetylgeopyxin A on gating properties of Voltage-Gated Channels in DRG Neurons ${ }^{a}$

\begin{tabular}{|c|c|c|}
\hline \multicolumn{3}{|l|}{ Calcium Total } \\
\hline & DMSO & 1-O-acetylgeopyxin A (20 $\mu \mathrm{M})$ \\
\hline \multicolumn{3}{|l|}{ Activation } \\
\hline$V_{1 / 2}(P=0.0188)$ & $-3.9 \pm 0.8(21)$ & $-6.7 \pm 0.8(21)^{* b}$ \\
\hline$k(P=0.1966)$ & $7.1 \pm 0.7(21)$ & $8.4 \pm 0.7(21)$ \\
\hline \multicolumn{3}{|l|}{ Inactivation } \\
\hline$V_{1 / 2}(P=0.0363)$ & $-26.8 \pm 0.8(19)$ & $-24.0 \pm 1.0(20)^{* b}$ \\
\hline$k(P=0.8775)$ & $-12.8 \pm 0.8(19)$ & $-12.6 \pm 1.0(20)$ \\
\hline \multicolumn{3}{|l|}{ Sodium } \\
\hline & DMSO & 1-O-Acetylgeopyxin A (20 $\mu \mathrm{M})$ \\
\hline \multicolumn{3}{|l|}{ Activation } \\
\hline$V_{1 / 2}(P=0.0001)$ & $-20.1 \pm 0.7(16)$ & $-14.9 \pm 0.8(19)^{* b}$ \\
\hline$k(P=0.0013)$ & $4.4 \pm 0.6(16)$ & $7.7 \pm 0.7(19)^{* b}$ \\
\hline \multicolumn{3}{|l|}{ Inactivation } \\
\hline$V_{1 / 2}(P=0.0006)$ & $-47.4 \pm 1.0(15)$ & $-40.6 \pm 1.4(18)^{* b}$ \\
\hline$k(P=0.1244)$ & $-10.9 \pm 0.9(15)$ & $-13.5 \pm 1.3(18)$ \\
\hline
\end{tabular}

${ }^{a}$ Values are means \pm SEM calculated from fits of the data from the indicated number of individual cells to the Boltzmann equation; $V_{1 / 2}$ midpoint potential $(\mathrm{mV})$ for voltage-dependent activation or inactivation; $k$, slope factor.

${ }^{\mathrm{b}}$ Significantly different from the value for DMSO $\left({ }^{*} \mathrm{P}<0.05\right.$; Student's $t$ test)

supported by a significant increase of the area under the curve between 1-O-acetylgeopyxin A treated animals the vehicle (saline) treated animals (Fig. 6b). Therefore, our results indicate that 1-O-acetylgeopyxin $\mathrm{A}$ has antinociceptive potential for HIV-induced sensory neuropathy.

\section{Discussion}

Ent-kauranes represent an important group of tetracyclic diterpene natural products and their structures are constituted by a perhydrophenantrene unit fused with a cyclopentane unit formed by a bridge of two carbons between C-8 and C-13 [5]. Diverse biological activities have been reported for ent-kaurane diterpenoids [6-15]. However, it has not yet been studied if these molecules have an antinociceptive effect. Therefore, the purpose of this work was to identify if ent-kauranes or their analogs have a therapeutic potential for pain relief.

In this context, in the present work we report that 1$O$-acetylgeopyxin A, a derivative of the new ent-kaurane diterpenoid geopyxin A, inhibits voltage-gated $\mathrm{Ca}^{2+}$ channels (Fig. 2) and voltage-gated $\mathrm{Na}^{+}$channels (Fig. 3 ), mediating the inhibition preferentially through the TTX-sensitive $\mathrm{Na}+$ channels (Fig. 4). Notably, 1-O-acetylgeopyxin A reversed mechanical allodynia on HIVinduced rodent model of sensory neuropathy (Fig. 5). The block of $\mathrm{Ca}^{2+}$ and tetrodotoxin-sensitive $\mathrm{Na}^{+}$channels supported the antinociceptive effect of 1-O-acetylgeopyxin A (Fig. 5). Nevertheless, it is important to determine the member(s) of voltage-gated $\mathrm{Ca}^{2+}$ channels underlying this inhibition, since rat DRG neurons express high-voltage activated (HVA; L-type $(\mathrm{CaV} 1), \mathrm{P} / \mathrm{Q}-$ type (CaV2.1), N-type (CaV2.2), and $\mathrm{R}$ type (CaV2.3)) and low voltage-activated (LVA; T-type (CaV3)) calcium channels. While not knowing which $\mathrm{Ca}^{2+}$ channel is targeted by 1-O-acetylgeopyxin $\mathrm{A}$ is a limitation of this study, dual or multi-target antagonists may have a better efficacy profile. Along these lines, it was recently reported that a derivatized version of a cationic N-type calcium channel blocker inhibited CaV2.2 (N-type) calcium channels as well as both tetrodotoxin-sensitive and tetrodotoxin-resistant voltage-gated sodium channels and was highly effective in producing long-lasting analgesia in mouse models of surgical and inflammatory pain [29]. Further, the molecular action of gabapentinoids may involve the calcium channel auxiliary protein $\alpha 2 \delta$ 1's action on CaV2.2 [30], thrombospondin [31], or Nmethyl-D-aspartate receptors [32], highlighting the potential of multi-target engagement to elicit analgesia.

Voltage-gated $\mathrm{Ca}^{2+}$ channels are critical targets in nociceptive transmission [24-26]. HVA $\mathrm{Ca}^{2+}$ channels, primarily the $\mathrm{CaV} 2$ family, are expressed in presynaptic terminals on the spinal cord dorsal horn and play an important role in neurotransmitter release and neuronal excitability [33-35], while LVA $\mathrm{Ca}^{2+}$ channels, in addition to participating in low-threshold exocytosis [36], are also involved in shaping action potentials, regulating neuronal firing patterns, lowering action potential thresholds, promoting burst firing, oscillatory behavior and enhancing synaptic excitation [37]. All these channels have been associated with painful phenotypes. For example, during neuropathic pain, an enhanced expression of the HVA calcium channels in DRG and presynaptic terminals has been reported [38, 39]. It is well known that the increased expression of these channels in the plasma membrane is mediated by their association with the auxiliary subunit $\alpha 2 \delta-1$, which has also been found to increase in neuropathic pain [40-42]. Likewise, $\mathrm{LVA} \mathrm{Ca}^{2+}$ channel expression is augmented in chronic pain [25, 43, 44]. Thus, in animal models of neuropathic pain, enhanced expression of these channels results in an increase in the maximum $\mathrm{Ca}^{2+}$ current density with the consequent increase in neuronal excitability [25,39]. Therefore, blocking $\mathrm{Ca}^{2+}$ channels with 1-O-acetylgeopyxin A (Fig. 2), resulted in the relief of mechanical allodynia (Fig. 5), which is consistent with previous reports using ziconotide [45], a N-type $\mathrm{Ca}^{2+}$ channel blocker and TTA-P2 [46], a T-type $\mathrm{Ca}^{2+}$ channel blocker to relieve pain $[45,46]$.

Voltage-gated sodium channels are also key components in the nociceptive pathway due to their electrical properties and roles in propagating electrical signaling. NaV1.7, NaV1.8, and NaV1.9 subtypes of NaV channels are preferentially found in the peripheral nervous system and are known to be crucial in the conduction of 


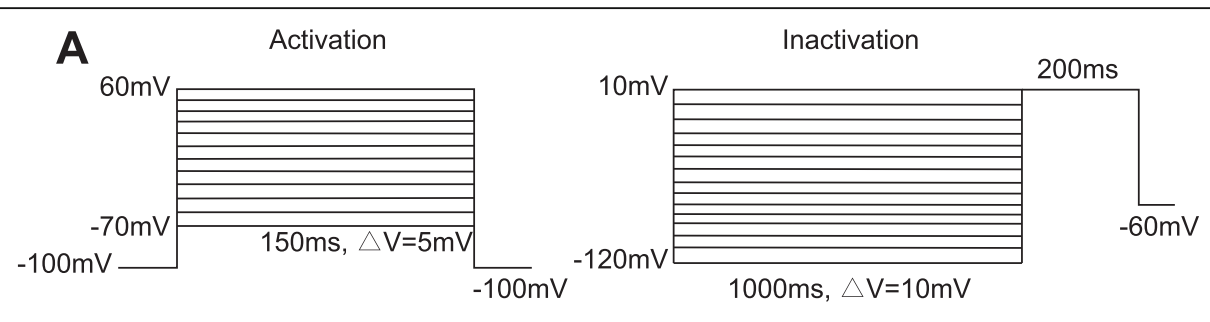

B

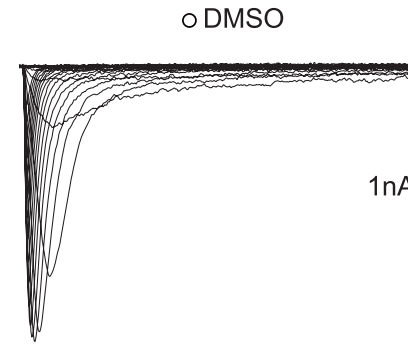

C

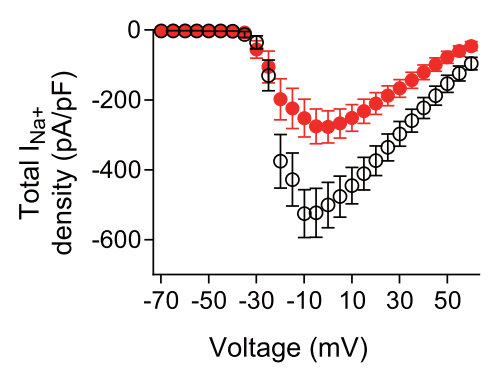

E

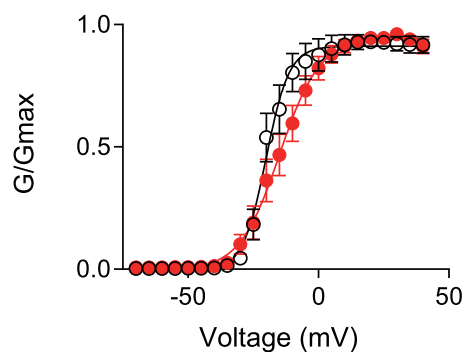

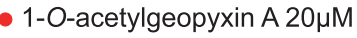

D

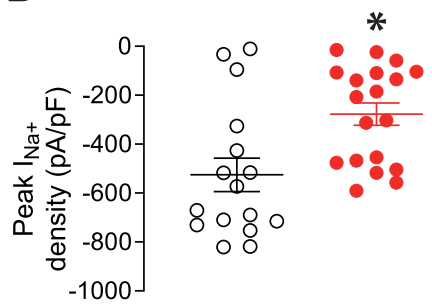

F

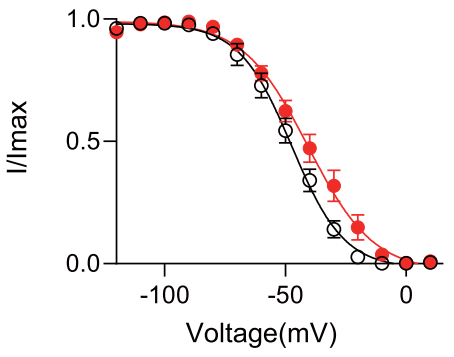

Fig. 3 1-O-acetylgeopyxin A inhibits total $\mathrm{Na}^{+}$currents in dorsal root ganglion (DRG) neurons. a Activation protocol: Currents were evoked by $150 \mathrm{~ms}$ pulse between -70 and $+60 \mathrm{mV}$ (+ $5 \mathrm{mV}$ steps) (left). Inactivation protocol: Cells were subjected to hyperpolarizing/ repolarizing pulses for $1 \mathrm{~s}$ between -120 and $10 \mathrm{mV}$ (+ $10 \mathrm{mV}$ steps), followed by a 0-mV test pulse for $200 \mathrm{~ms}$ (right). b Representative traces of Na ${ }^{+}$currents from DRG sensory neurons treated with $0.1 \%$ DMSO (control) or $20 \mu \mathrm{M}$ 1-O-acetylgeopyxin A. c, d Summary ( \pm SEM) of the normalized (pA/pF) sodium current density versus voltage relationship (c) and peak $\mathrm{Na}^{+}$current density at $-10 \mathrm{mV}$ (mean \pm SEM) (d) from DRG neurons treated as indicated. e, $\mathbf{f}$ Boltzmann fits for normalized conductance, G/Gmax, voltage relations for voltage dependent activation (e) and inactivation (f) of sensory neurons treated as indicated. $V_{1 / 2}$ values for activation and inactivation are presented in Table 1. Asterisk indicate statistical significance compared with cells treated with $0.1 \%$ DMSO $\left({ }^{*} \mathrm{P}<0.05\right.$, unpaired two-tailed Student's t test, $n=16-19$ per condition)

nociceptive stimuli [20]. These channels can be classified according to their sensitivity (NaV1.7) and resistance (NaV1.8 and NaV1.9) to TTX [20] in sensory neurons. Nav1.8 is preferentially expressed in large and medium DRG neurons [47] and NaV1.9 in small-diameter DRG neurons [48], while NaV1.7 is expressed in small- and medium-diameter DRG neurons (and rarely in largediameter neurons). NaV1.7 produces a rapidly activating and inactivating TTX-sensitive current [49]. This channel is well suited to low-frequency firing in nociceptive C-fibers due to its slow repriming nature [49] and is considered a threshold channel due to its ability to boost subthreshold stimuli, thereby increase action potential firing frequency [50]. The TTX-R current produced by $\mathrm{NaV} 1.8$ acts as the main contributor to the upstroke of action potentials [51]. NaV1.9 can be activated at voltages close to resting membrane potential and generates a persistent TTX-R current that has very slow gating 


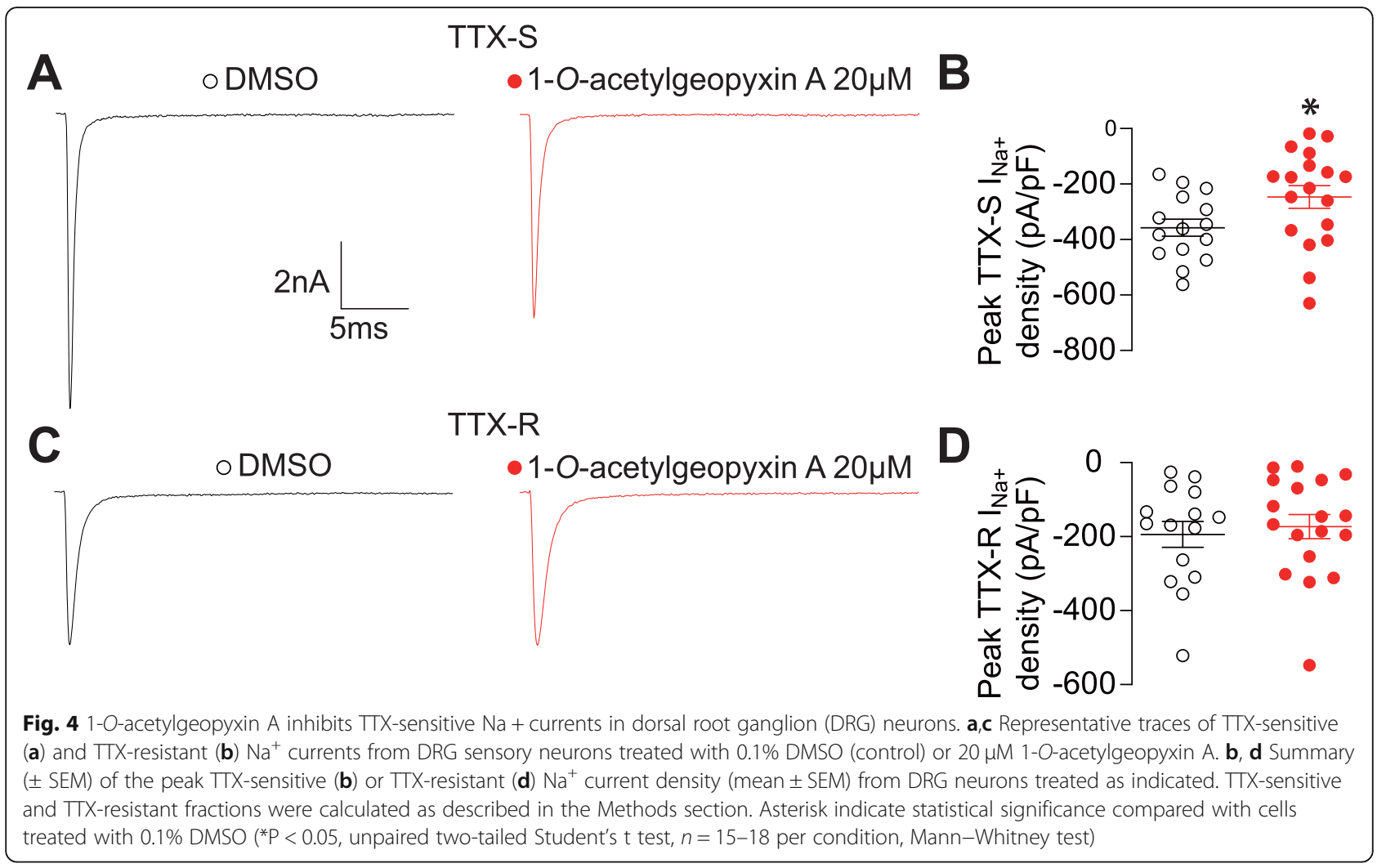

kinetics. Therefore, this channel acts as a modulator of membrane excitability through persistent inward currents [48]. Several rodent studies have demonstrated the importance of these channels in pain sensation. Mice lacking NaV1.7 in NaV1.8 positive nociceptors displayed insensitivity to painful stimuli [52]. Similarly, deletion of NaV1.8 in sensory neurons reduces the sensitivity to noxious mechanical [51] and NaV1.9 knockout mice do not develop thermal hyperalgesia after complete Freund's adjuvant or carrageenan injection [53]. Our data shows that 1$\mathrm{O}$-acetylgeopyxin A did not affect NaV1.8 and Nav1.9 currents (Fig. 4). Hence, 1-O-acetylgeopyxin A appears to be involved in inhibition of pan-TTX-S $\mathrm{Na}^{+}$currents. Overall, the inhibition of total $\mathrm{Na}^{+}$currents in sensory neurons (Fig. 3), likely via its action on NaV1.7 (Fig. 4) as well as an inhibition of sensory neuron excitability (Fig. 5) collectively contributes to inhibition of nociceptive behavior (Fig. 6).

Thus, our findings support the use of 1-O-acetylgeopyxin $\mathrm{A}$ as a lead compound, positioning its structure for future modifications and optimizations for the eventual production of more effective antinociceptive drugs.

\section{Methods}

\section{Animals}

Adult Sprague-Dawley rats (females, 225 - 250 g; Harlan Laboratories) were kept in light-controlled (12 h light/ $12 \mathrm{~h}$ dark cycle; lights on 07:00-19:00) and temperature- controlled $\left(23 \pm 2{ }^{\circ} \mathrm{C}\right)$ rooms with access to rodent chow and water as needed. The University of Arizona's College of Medicine Institutional Animal Care and Use Committee (IACUC) sanctioned all experiments. All experiments were performed per guidelines recommended published by National Institutes of Health Guide for Care and Use of Laboratory Animals and adhered to International Association for the Study of Pain ethical guidelines. For the behavioral experiments, rats were randomly assigned to control or treatment conditions. Animals were initially housed three/cage and singly after the intrathecal cannulation on a $12 \mathrm{~h}$ dark-light cycle with ad libitum food/water. Experimenters performing the behaviors were kept blinded to the experimental treatment conditions.

\section{Materials}

All utilized chemicals and reagents were purchased from Sigma (St. Louis, MO) unless otherwise stated. The natural products and their derivatives used in this study, geopyxin $\mathrm{A}, 1-\mathrm{O}$-acetylmethylgeopyxin $\mathrm{A}$, methylgeopyxin $\mathrm{A}, 1-\mathrm{O}$-acetylgeopyxin $\mathrm{A}$ and geopyxin $\mathrm{C}$ were obtained as described previously [5].

\section{Preparation of acutely dissociated dorsal root ganglion neurons}

Dorsal root ganglia from all spinal levels were cultured using methods as described previously [54, 55]. 

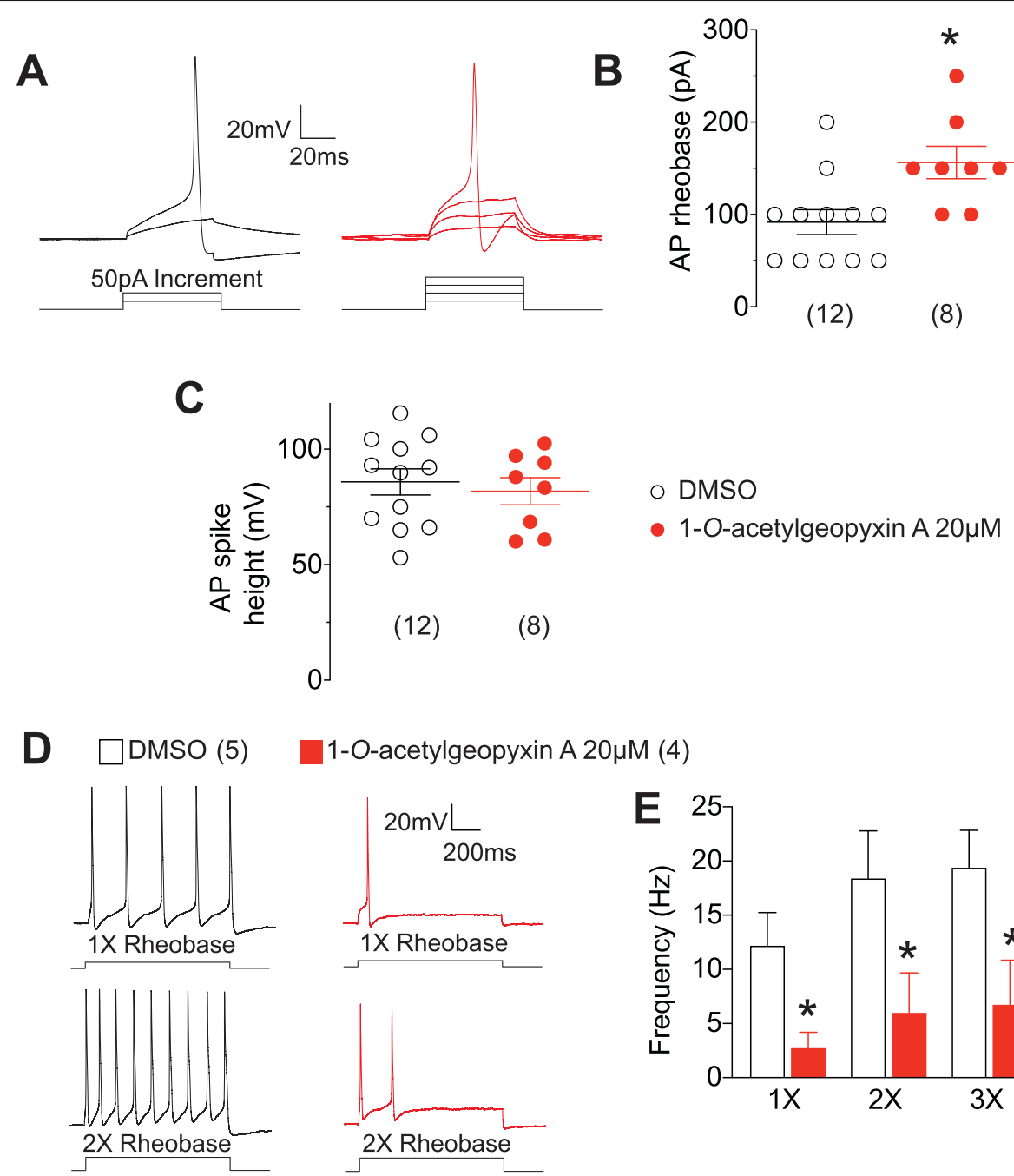

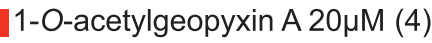
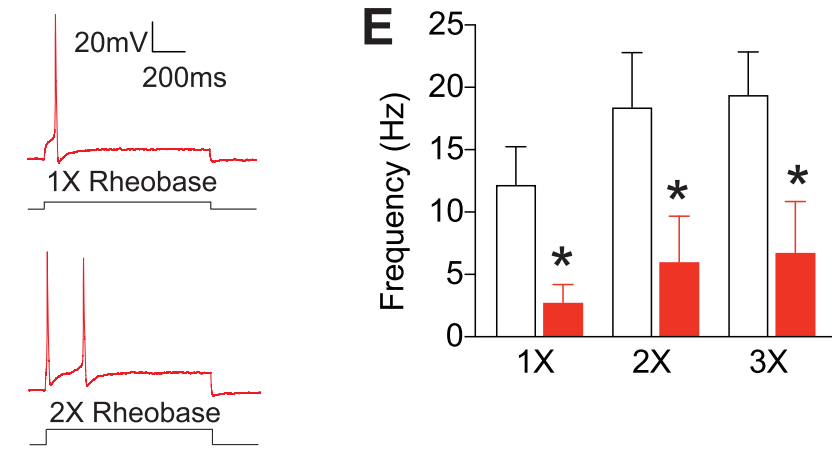

Fig. 5 1-O-acetylgeopyxin A inhibits excitability in dorsal root ganglion (DRG) neurons. a Representative recordings in response to various steps of depolarizing current to measure rheobase (i.e. current required for eliciting the first action potential (AP)) in sensory neurons incubated with DMSO or 20 MM 1-O-acetylgeopyxin A. Summary of the measured mean ( \pm SEM) rheobase (b) and AP spike height (in millivolts, mV) (c) in indicated conditions ( $n=8-12$ as indicated; ( ${ }^{*} P=0.0085$, unpaired two-tailed Student's $t$ test). $\mathbf{d}$ Representative traces of action potentials displayed by DRG neurons in culture after incubation with DMSO or $20 \mu \mathrm{M} 1$-0-acetylgeopyxin A in response to current injections of 1x or $2 x$ rheobase. e Bar graphs of mean frequency of APs in response to current injections of $1 x, 2 x$, or $3 x$ rheobase. ( ${ }^{*} P<0.05$, one-way ANOVA with Dunnett's post hoc test)

Dissociated DRG neurons were subsequently plated onto 12- or 15-mm poly-D-lysine and laminin-coated coverslips and cultured for up to $48 \mathrm{~h}$ in media consisting of DMEM (1\% penicillin/streptomycin sulfate from 10, $000 \mu \mathrm{g} / \mathrm{mL}$ stock, $10 \%$ fetal bovine serum (Hyclone)), and $30 \mathrm{ng} / \mathrm{mL}$ nerve growth factor).

\section{Calcium imaging in acutely dissociated rat dorsal root ganglia neurons}

Calcium imaging was done as described previously [17]. Since the $\mathrm{K}^{+}$concentration inside the cell is 140 $\mathrm{mM}, \mathrm{Cl}^{-}$is $10 \mathrm{mM}$, and $\mathrm{Na}^{+}$is $15 \mathrm{mM}$, then at room temperature (25 degree Celsius), using the Nernst equation, a trigger with $40 \mathrm{mM} \mathrm{KCl}$ will bring the membrane voltage to $-32.2 \mathrm{mV}$, which activates mostly LVA calcium channels. When challenged with $90 \mathrm{mM} \mathrm{KCl}$, the membrane voltage changes to -11.4 $\mathrm{mV}$, which activates HVA; and at this potential, most LVA is already inactivated (for example, see [56] or [57]). Dorsal root ganglion neurons were bathed for $30 \mathrm{~min}$ at $37^{\circ} \mathrm{C}$ with a concentration of $3 \mu \mathrm{M}$ Fura-2 AM (Cat\# F1221, Thermo Fisher, stock solution prepared at $1 \mathrm{mM}$ in DMSO, $0.02 \%$ pluronic acid, Cat\#P3000MP, Life Technologies) to survey changes in intracellular calcium $\left(\left[\mathrm{Ca}^{2+}\right] \mathrm{c}\right)$ as described before [58]. The changes in $\left[\mathrm{Ca}^{2+}\right] \mathrm{c}$ changes were examined with a ratio of F340/ F380, calculated after subtracting background from both channels. 
- Vehicle $2 \mu \mathrm{g} / 5 \mu \mathrm{l}, 1-O$-acetylgeopyxin A

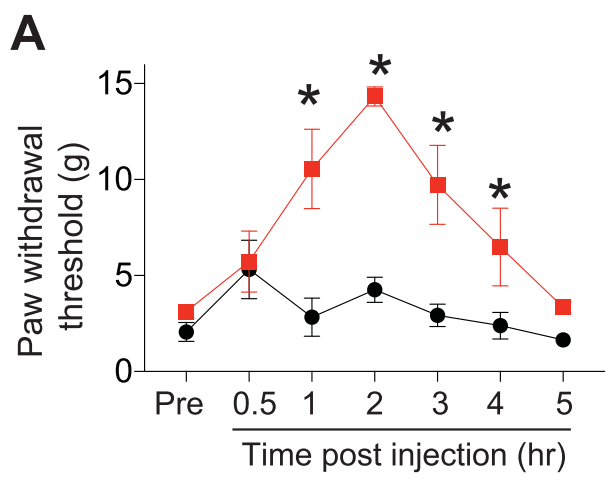

B

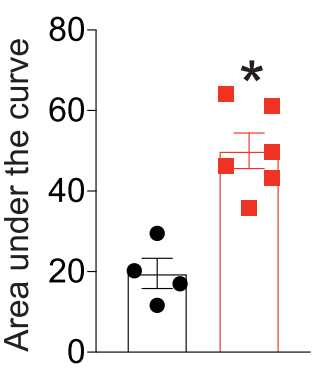

Fig. 6 1-O-acetylgeopyxin A reduces gp120-induced mechanical allodynia. a Paw withdrawal threshold of adult male rats $(n=4-6)$ was measured 15 days after three intrathecal injections of gp120. Rats were treated with (intrathecally (i.th.) via catheter) saline (vehicle) or 1-O-acetylgeopyxin A $(2 \mu \mathrm{g} / 5 \mu \mathrm{L})$ as indicated. Asterisks indicate statistical significance compared with saline treatment ${ }^{*} p<0.05$; two-way ANOVA with a StudentNeuman-Kuels post hoc test). b Area under the curve was derived as indicated above using GraphPad Prism. Statistical significance is indicated by asterisks ( ${ }^{*} p<0.05$, Mann-Whitney test) in comparison to vehicle-treated rats. Experimenter was blinded to the treatment condition.

\section{Whole-cell electrophysiological recordings of calcium currents in acutely dissociated DRG neurons}

Recordings of total calcium currents were obtained using recording solutions and protocols (also illustrated in the figures) described earlier [18]. The internal solution consisted of (in $\mathrm{mM}$ ): $150 \mathrm{CsCl}_{2}, 10 \mathrm{HEPES}, 5 \mathrm{Mg}$-ATP, and 5 BAPTA (pH 7.3, mOsm/L $=290-310)$ and external solution contained (in mM): 110 NMDG, $10 \mathrm{BaCl}_{2}, 30$ TEA-Cl, 10 HEPES, 10 glucose and $10 \mu \mathrm{M}$ HEPES (pH $7.3, \operatorname{mosM} / \mathrm{L}=310-315$ ). The neurons were subjected to current-density $(\mathrm{I}-\mathrm{V})$ and activation/inactivation voltage protocols as previously described and shown in the figures [18].

\section{Whole-cell electrophysiological recordings of sodium currents in acutely dissociated DRG neurons}

Recordings were obtained from acutely dissociated DRG neurons as described by us before $[55,59,60]$. The internal solution consisted of (in $\mathrm{mM}$ ): $140 \mathrm{CsF}, 10 \mathrm{NaCl}$, 1.1Cs-EGTA, and 15 HEPES ( $\mathrm{pH} 7.3, \mathrm{mOsm} / \mathrm{L}=290$ 310 ) and external solution contained (in $\mathrm{mM}$ ): $140 \mathrm{NaCl}$, 30 tetraethylammonium chloride, $10 \mathrm{D}$-glucose, $3 \mathrm{KCl}, 1$ $\mathrm{CaCl} 2,0.5 \mathrm{CdCl}_{2}, 1 \mathrm{MgCl}_{2}$, and 10 HEPES ( $\mathrm{pH} 7.3$, $\operatorname{mosM} / \mathrm{L}=310-315)$. The neurons were subjected to current-density (I- V) and activation/inactivation voltage protocols as previously described and shown in the figures $[18,21]$. Because of differential inactivation kinetics of TTX-R and TTX-S channels, the fast inactivation protocol permitted separation of electrically isolated TTX-R (current available following a $-40 \mathrm{mV}$ prepulse) from the total current (current left after a $-120 \mathrm{mV}$ prepulse), to obtain TTX-S currents, as previously reported [21]. TTX-R current was estimated by a $200 \mathrm{~ms}$ test pulse to $10 \mathrm{mV}$ following $1000 \mathrm{~ms}$ prepulse at $-40 \mathrm{mV}$ to inactivate the TTX-S component [61]. To test for TTX-resistant currents, I-V protocol was conducted after $5 \mathrm{~min}$ of bathing in a concentration of $1 \mu \mathrm{M}$ TTX. Pipettes with 1-3M $\Omega$ resistance were used for all recordings.

Whole-cell patch recording of spontaneous and evoked action potential in acutely dissociated DRG neurons

Current-clamp recordings were performed as described previously [62]. Briefly, the internal solution contained (in $\mathrm{mM}$ ): $137 \mathrm{KCl}, 10 \mathrm{NaCl}, 1 \mathrm{MgCl}_{2}, 1$ EGTA, and 10 HEPES adjusted to $\mathrm{pH} 7.3$ with $\mathrm{KOH}$. The external solution contained (in $\mathrm{mM}$ ): $154 \mathrm{NaCl}, 5.6 \mathrm{KCl}, 2 \mathrm{CaCl}_{2}, 1$ $\mathrm{MgCl}_{2}, 10$ Glucose and 8 HEPES adjusted to $\mathrm{pH} 7.4$ with $\mathrm{NaOH}$. The DRG neurons with a resting potential more hyperpolarized than $-40 \mathrm{~m} \mathrm{~V}$, stable baseline recordings, and evoked spikes that overshot $0 \mathrm{mV}$ were used for experiments and analysis. To measure DRG excitability, first, a series of current steps that were 500-millisecond in duration and of 10-pA steps from - $50 \mathrm{pA}$ were used to determine the rheobase; second, neurons were held at resting potentials and injected with a series of 1-s steps of depolarizing current with an amplitude of $1 \times$ rheobase, $2 \times$ rheobase and $3 \times$ rheobase. The DRG neurons were then held at $0 \mathrm{pA}$ to record spontaneous action potential for $5 \mathrm{~min}$. Bridge balance was compensated to above $60 \%$ for the recorded DRG neurons. All recordings were made at room temperature.

\section{Intrathecal catheterization}

For drug administration via intrathecal (i.t.) route, rats were implanted with catheters as described by Yaksh and Rudy [63]. 


\section{Assessment of mechanical allodynia}

Allodynia was tested as described previously [17]. Data was analyzed as reported by Chaplan et al. [64] using Dixon's nonparametric method.

\section{HIV-induced sensory neuropathy}

Mechanical allodynia is produced by i.th. injection of human immunodeficiency virus-1 (HIV-1) envelope glycoprotein, gp120 [28]. The compounds were assessed for their ability to affect mechanical allodynia at 10-14 days after the first injection of gp120.

\section{Statistical analyses}

All values represent the mean \pm SEM. Data sets were all tested with a D'agostino-Pearson test for normality (Graphpad Prism 8 Software). Following the result of the normality test, statistical significance was tested using the appropriate parametric or nonparametric Student's t test or analysis of variance (ANOVA), after which we performed post hoc comparisons (Tukey). Von Frey behavioral data sets were analyzed by two-way ANOVA (Tukey posthoc test). Statistical significance was inferred for all $p \leq 0.05$. GraphPad Prism 8 was used for all graphs. No data points were excluded in our studies.

\section{Abbreviations}

$\mathrm{KCl}$ : Potassium chloride; DRG: Dorsal root ganglia; TTX: Tetrodotoxin; TTXS: Tetrodotoxin-sensitive; TTX-R: Tetrodotoxin-resistant; LVA: Low voltageactivated; HVA: High voltage-activated; $V_{1 / 2}$ : Half-maximal activation; $k$ : Slope; HIV gp120: Human immunodeficiency virus envelope glycoprotein of 120 KDa

\section{Authors' contributions}

YZ, SC, EMKW, YJ, SSB, SL and AM performed the experiments. YZ, SC, EMKW, YJ, SSB, SL analyzed the data. KG and RK wrote the manuscript. AALG and RK designed/supervised the overall project. All authors reviewed the manuscript. The authors read and approved the final manuscript.

\section{Funding}

This work is supported by a National Institutes of Health awards to R.K. (1R01NS098772) and A.A.L.G. (R01CA90265).

\section{Availability of data and materials}

Please contact author for data requests.

\section{Ethics approval and consent to participate}

Not applicable.

Ethics approval for use of animals

The University of Arizona's College of Medicine Institutional Animal Care and Use Committee (IACUC) sanctioned all experiments.

\section{Consent for publication}

Not applicable.

\section{Competing interests}

R. Khanna is the co-founder of Regulonix LLC, a company developing nonopioids drugs for chronic pain. In addition, R. Khanna has patents US10287334 and US10441586 issued to Regulonix LLC. The other authors declare that the research was conducted in the absence of any commercial or financial relationships that could be construed as a potential conflict of interest.

\section{Author details}

'Department of Clinical Laboratory, the First Hospital of Jilin University, Changchun 130021, China. ${ }^{2}$ Department of Pharmacology, College of Medicine, University of Arizona, 1501 North Campbell Drive, P.O. Box 245050, Tucson, AZ 85724, USA. ${ }^{3}$ Southwest Center for Natural Products Research, School of Natural Resources \& the Environment, College of Agriculture \& Life Sciences, The University of Arizona, Tucson, AZ 85724, USA. ${ }^{4}$ Neuroscience Graduate Interdisciplinary Program, College of Medicine, Tucson, AZ 85724, USA. ${ }^{5}$ The Center for Innovation in Brain Sciences, The University of Arizona Health Sciences, Tucson, AZ 85724, USA.

Received: 3 March 2020 Accepted: 4 May 2020

Published online: 11 May 2020

\section{References}

1. Carr DB, Goudas LC. Acute pain. Lancet. 1999:353(9169):2051-8.

2. Institute of Medicine (US) Committee on Advancing Pain Research Cr, and Education. Relieving pain in America: a blueprint for transforming prevention, care, education, and research; 2011.

3. Woolf CJ. What is this thing called pain? J Clin Invest. 2010;120(11):3742-4.

4. Dowell D, Haegerich TM, Chou R. CDC guideline for prescribing opioids for chronic pain - United States, 2016. MMWR Recomm Rep. 2016;65(1):1-49.

5. Wijeratne EM, Bashyal BP, Liu MX, Rocha DD, Gunaherath GM, U'Ren JM, et al. Geopyxins A-E, ent-kaurane diterpenoids from endolichenic fungal strains Geopyxis aff. Majalis and Geopyxis sp. AZ0066: structure-activity relationships of geopyxins and their analogues. J Nat Prod. 2012;75(3):361-9.

6. Hou AJ, Li ML, Jiang B, Lin ZW, Ji SY, Zhou YP, et al. New 7,20:14,20-diepoxy ent-kauranoids from Isodon xerophilus. J Nat Prod. 2000;63(5):599-601.

7. Rosselli S, Bruno M, Maggio A, Bellone G, Chen TH, Bastow KF, et al. Cytotoxic activity of some natural and synthetic ent-kauranes. J Nat Prod. 2007;70(3):347-52

8. Bai N, He K, Zhou Z, Tsai ML, Zhang L, Quan Z, et al. Ent-kaurane diterpenoids from Rabdosia rubescens and their cytotoxic effects on human cancer cell lines. Planta Med. 2010;76(2):140-5

9. Aimond A, Calabro K, Audoin C, et al. Cytotoxic and Anti-Inflammatory Effects of Ent-Kaurane Derivatives Isolated from the Alpine Plant Sideritis hyssopifolia. Molecules (Basel, Switzerland). 2020;25(3). https://doi.org/10. 3390/molecules25030589.

10. Yeh SH, Chang FR, Wu YC, Yang YL, Zhuo SK, Hwang TL. An antiinflammatory ent-kaurane from the stems of Annona squamosa that inhibits various human neutrophil functions. Planta Med. 2005;71(10):904-9.

11. Hwang BY, Lee JH, Koo TH, Kim HS, Hong YS, Ro JS, et al. Kaurane diterpenes from Isodon japonicus inhibit nitric oxide and prostaglandin E2 production and NF-kappaB activation in LPS-stimulated macrophage RAW264.7 cells. Planta Med. 2001;67(5):406-10.

12. Meade-Tollin LC, Wijeratne EM, Cooper D, Guild M, Jon E, Fritz A, et al. Ponicidin and oridonin are responsible for the antiangiogenic activity of Rabdosia rubescens, a constituent of the herbal supplement PC SPES. J Nat Prod. 2004;67(1):2-4

13. Saepou S, Pohmakotr M, Reutrakul V, Yoosook C, Kasisit J, Napaswad C, et al. Anti-HIV-1 diterpenoids from leaves and twigs of Polyalthia sclerophylla. Planta Med. 2010:76(7):721-5.

14. Ertaş A, Oztürk M, Boğa M, Topçu G. Antioxidant and anticholinesterase activity evaluation of ent-kaurane diterpenoids from Sideritis arguta. J Nat Prod. 2009;72(3):500-2.

15. Ko HH, Chang WL, Lu TM. Antityrosinase and antioxidant effects of entkaurane diterpenes from leaves of Broussonetia papyrifera. J Nat Prod. 2008; 71(11):1930-3.

16. Bellampalli SS, Ji Y, Moutal A, Cai S, Wijeratne EMK, Gandini MA, et al. Betulinic acid, derived from the desert lavender Hyptis emoryi, attenuates paclitaxel-, HIV-, and nerve injury-associated peripheral sensory neuropathy via block of N- and T-type calcium channels. Pain. 2019;160(1):117-35.

17. Cai S, Bellampalli SS, Yu J, Li W, Ji Y, Wijeratne EMK, et al. (-)-Hardwickiic acid and Hautriwaic acid induce Antinociception via blockade of Tetrodotoxin-sensitive voltage-dependent sodium channels. ACS Chem Nerosci. 2019;10(3):1716-28.

18. Shan Z, Cai S, Yu J, Zhang Z, Vallecillo TGM, Serafini MJ, et al. Reversal of peripheral neuropathic pain by the small-molecule natural product Physalin F via block of CaV2.3 (R-type) and CaV2.2 (N-type) voltage-gated calcium channels. ACS Chem Nerosci. 2019;10(6):2939-55. 
19. Wheeler DG, Groth RD, Ma H, Barrett CF, Owen SF, Safa P, et al. Ca(V)1 and $\mathrm{ca}(\mathrm{V}) 2$ channels engage distinct modes of $\mathrm{ca}(2+)$ signaling to control CREBdependent gene expression. Cell. 2012;149(5):1112-24.

20. Kanellopoulos AH, Matsuyama A. Voltage-gated sodium channels and painrelated disorders. Clin Sci (Lond). 2016;130(24):2257-65.

21. Dustrude ET, Moutal A, Yang X, Wang Y, Khanna M, Khanna R. Hierarchical CRMP2 posttranslational modifications control NaV1.7 function. Proc Natl Acad Sci U S A. 2016;113(52):E8443-E52.

22. Hoeijmakers JG, Faber CG, Merkies IS, Waxman SG. Painful peripheral neuropathy and sodium channel mutations. Neurosci Lett. 2015;596:51-9.

23. Waxman SG, Merkies ISJ, Gerrits MM, Dib-Hajj SD, Lauria G, Cox JJ, et al. Sodium channel genes in pain-related disorders: phenotype-genotype associations and recommendations for clinical use. Lancet Neurol. 2014;13(11):1152-60.

24. Bourinet E, Alloui A, Monteil A, Barrère C, Couette B, Poirot $O$, et al. Silencing of the Cav3.2 T-type calcium channel gene in sensory neurons demonstrates its major role in nociception. EMBO J. 2005;24(2):315-24.

25. Jagodic MM, Pathirathna S, Joksovic PM, Lee W, Nelson MT, Naik AK, et al. Upregulation of the T-type calcium current in small rat sensory neurons after chronic constrictive injury of the sciatic nerve. J Neurophysiol. 2008;99(6):3151-6.

26. Chaplan SR, Pogrel JW, Yaksh TL. Role of voltage-dependent calcium channel subtypes in experimental tactile allodynia. J Pharmacol Exp Ther. 1994;269(3):1117-23.

27. Yuan SB, Shi Y, Chen J, Zhou X, Li G, Gelman BB, et al. Gp120 in the pathogenesis of human immunodeficiency virus-associated pain. Ann Neurol. 2014;75(6):837-50.

28. Milligan ED, O'Connor KA, Nguyen KT, Armstrong CB, Twining C, Gaykema $\mathrm{RP}$, et al. Intrathecal HIV-1 envelope glycoprotein gp120 induces enhanced pain states mediated by spinal cord proinflammatory cytokines. J Neurosci. 2001;21(8):2808-19.

29. Lee S, Jo S, Talbot S, Zhang HB, Kotoda M, Andrews NA, et al. Novel charged sodium and calcium channel inhibitor active against neurogenic inflammation. Elife. 2019;8:e48118.

30. Rock DM, Kelly KM, Macdonald RL. Gabapentin actions on ligand- and voltagegated responses in cultured rodent neurons. Epilepsy Res. 1993;16(2):89-98.

31. Eroglu C, Allen NJ, Susman MW, O'Rourke NA, Park CY, Ozkan E, et al. Gabapentin receptor alpha2delta-1 is a neuronal thrombospondin receptor responsible for excitatory CNS synaptogenesis. Cell. 2009;139(2):380-92.

32. Chen J, Li L, Chen SR, Chen H, Xie JD, Sirrieh RE, et al. The alpha2delta-1-NMDA receptor complex is critically involved in neuropathic pain development and gabapentin therapeutic actions. Cell Rep. 2018;22(9):2307-21.

33. Catterall WA, Few AP. Calcium channel regulation and presynaptic plasticity. Neuron. 2008;59(6):882-901.

34. Westenbroek RE, Hell JW, Warner C, Dubel SJ, Snutch TP, Catterall WA. Biochemical properties and subcellular distribution of an N-type calcium channel alpha 1 subunit. Neuron. 1992;9(6):1099-115.

35. Dietrich D, Kirschstein T, Kukley M, Pereverzev A, von der Brelie C, Schneider T, et al. Functional specialization of presynaptic Cav2.3 Ca2+ channels. Neuron. 2003;39(3):483-96.

36. Weiss N, Hameed S, Fernandez-Fernandez JM, Fablet K, Karmazinova M, Poillot C, et al. A ca(v)3.2/syntaxin-1A signaling complex controls T-type channel activity and low-threshold exocytosis. J Biol Chem. 2012;287(4):2810-8.

37. Iftinca MC, Zamponi GW. Regulation of neuronal T-type calcium channels. Trends Pharmacol Sci. 2009;30(1):32-40.

38. Fossat P, Dobremez E, Bouali-Benazzouz R, Favereaux A, Bertrand SS, Kilk K, et al. Knockdown of $\mathrm{L}$ calcium channel subtypes: differential effects in neuropathic pain. J Neurosci. 2010;30(3):1073-85.

39. Cizkova D, Marsala J, Lukacova N, Marsala M, Jergova S, Orendacova J, et al. Localization of $\mathrm{N}$-type $\mathrm{Ca} 2+$ channels in the rat spinal cord following chronic constrictive nerve injury. Exp Brain Res. 2002;147(4):456-63.

40. Luo ZD, Chaplan SR, Higuera ES, Sorkin LS, Stauderman KA, Williams ME, et al. Upregulation of dorsal root ganglion (alpha)2(delta) calcium channel subunit and its correlation with allodynia in spinal nerve-injured rats. J Neurosci. 2001;21(6):1868-75.

41. Newton RA, Bingham S, Case PC, Sanger GJ, Lawson SN. Dorsal root ganglion neurons show increased expression of the calcium channel alpha2delta-1 subunit following partial sciatic nerve injury. Brain Res Mol Brain Res. 2001;95(1-2):1-8

42. Bauer CS, Nieto-Rostro M, Rahman W, Tran-Van-Minh A, Ferron L, Douglas L, et al. The increased trafficking of the calcium channel subunit alpha2delta-1 to presynaptic terminals in neuropathic pain is inhibited by the alpha2delta ligand pregabalin. J Neurosci. 2009;29(13):4076-88.
43. Takahashi T, Aoki Y, Okubo K, Maeda Y, Sekiguchi F, Mitani K, et al. Upregulation of ca(v)3.2 T-type calcium channels targeted by endogenous hydrogen sulfide contributes to maintenance of neuropathic pain. Pain. 2010;150(1):183-91.

44. Gomez K, Calderón-Rivera A, Sandoval A, González-Ramírez R, Vargas-Parada A, Ojeda-Alonso J, et al. Cdk5-dependent phosphorylation of ca. J Neurosci. 2020;40(2):283-96.

45. Lynch SS, Cheng CM, Yee JL. Intrathecal ziconotide for refractory chronic pain. Ann Pharmacother. 2006:40(7-8):1293-300.

46. Choe W, Messinger RB, Leach E, Eckle VS, Obradovic A, Salajegheh R, et al. TTA$\mathrm{P} 2$ is a potent and selective blocker of T-type calcium channels in rat sensory neurons and a novel antinociceptive agent. Mol Pharmacol. 2011;80(5):900-10.

47. Shields SD, Ahn HS, Yang Y, Han C, Seal RP, Wood JN, et al. Nav1.8 expression is not restricted to nociceptors in mouse peripheral nervous system. Pain. 2012;153(10):2017-30

48. Dib-Hajj S, Black JA, Cummins TR, Waxman SG. NaN/Nav1.9: a sodium channel with unique properties. Trends Neurosci. 2002;25(5):253-9.

49. Herzog Rl, Cummins TR, Ghassemi F, Dib-Hajj SD, Waxman SG. Distinct repriming and closed-state inactivation kinetics of Nav1.6 and Nav1.7 sodium channels in mouse spinal sensory neurons. J Physiol. 2003;551(Pt 3):741-50.

50. Dib-Hajj SD, Cummins TR, Black JA, Waxman SG. From genes to pain: Na v 1.7 and human pain disorders. Trends Neurosci. 2007:30(11):555-63.

51. Renganathan M, Cummins TR, Waxman SG. Contribution of $\mathrm{Na}(\mathrm{V}) 1.8$ sodium channels to action potential electrogenesis in DRG neurons. J Neurophysiol. 2001;86(2):629-40

52. Nassar MA, Stirling LC, Forlani G, Baker MD, Matthews EA, Dickenson AH, et al. Nociceptor-specific gene deletion reveals a major role for Nav1.7 (PN1) in acute and inflammatory pain. Proc Natl Acad Sci U S A. 2004;101(34):12706-11.

53. Priest BT, Murphy BA, Lindia JA, Diaz C, Abbadie C, Ritter AM, et al. Contribution of the tetrodotoxin-resistant voltage-gated sodium channel NaV1.9 to sensory transmission and nociceptive behavior. Proc Natl Acad Sci U S A. 2005;102(26):9382-7.

54. François-Moutal L, Wang Y, Moutal A, Cottier KE, Melemedjian OK, Yang X, et al. A membrane-delimited N-myristoylated CRMP2 peptide aptamer inhibits CaV2.2 trafficking and reverses inflammatory and postoperative pain behaviors. Pain. 2015;156(7):1247-64.

55. Moutal A, Wang Y, Yang X, Ji Y, Luo S, Dorame A, et al. Dissecting the role of the CRMP2-neurofibromin complex on pain behaviors. Pain. 2017;158(11): 2203-21.

56. Piekarz AD, Due MR, Khanna M, Wang B, Ripsch MS, Wang R, et al. CRMP-2 peptide mediated decrease of high and low voltage-activated calcium channels, attenuation of nociceptor excitability, and anti-nociception in a model of AIDS therapy-induced painful peripheral neuropathy. Mol Pain. 2012;8(1):54.

57. Chi XX, Schmutzler BS, Brittain JM, Hingtgen CM, Nicol GD, Khanna R. Regulation of N-type voltage-gated calcium (CaV2.2) channels and transmitter release by collapsin response mediator protein-2 (CRMP-2) in sensory neurons. J Cell Sci. 2009;23:4351-62.

58. Brittain JM, Duarte DB, Wilson SM, Zhu W, Ballard C, Johnson PL, et al. Suppression of inflammatory and neuropathic pain by uncoupling CRMP-2 from the presynaptic $\mathrm{Ca}^{2+}$ channel complex. Nat Med. 2011;17(7):822-9.

59. Dustrude ET, Wilson SM, Ju W, Xiao Y, Khanna R. CRMP2 protein SUMOylation modulates NaV1.7 channel trafficking. J Biol Chem. 2013; 288(34):24316-31.

60. Moutal A, Li W, Wang Y, Ju W, Luo S, Cai S, et al. Homology-guided mutational analysis reveals the functional requirements for antinociceptive specificity of collapsin response mediator protein 2-derived peptides. $\mathrm{Br} J$ Pharmacol. 2018;175(12):2244-60.

61. Roy ML, Narahashi T. Differential properties of tetrodotoxin-sensitive and tetrodotoxin-resistant sodium channels in rat dorsal root ganglion neurons. J Neurosci. 1992;12(6):2104-11.

62. Moutal A, Yang X, Li W, Gilbraith KB, Luo S, Cai S, et al. CRISPR/Cas9 editing of Nf1 gene identifies CRMP2 as a therapeutic target in neurofibromatosis type 1related pain that is reversed by (S)-Lacosamide. Pain. 2017;158(12):2301-19.

63. Yaksh TL, Rudy TA. Chronic catheterization of the spinal subarachnoid space. Physiol Behav. 1976;17(6):1031-6.

64. Chaplan SR, Bach FW, Pogrel JW, Chung JM, Yaksh TL. Quantitative assessment of tactile allodynia in the rat paw. J Neurosci Methods. 1994;53(1):55-63.

\section{Publisher's Note}

Springer Nature remains neutral with regard to jurisdictional claims in published maps and institutional affiliations. 